\title{
De la reforma de la Administración
}

al control de calidad de los servicios públicos

\section{Miguel Beltrán Villalva *}

Con frecuencia se insiste, desde todas las posiciones ideológicas, en la necesidad de llevar a cabo cambios más o menos profundos en las Administraciones públicas, de suerte que los ciudadanos reciban mejores servicios y vean bien utilizados sus impuestos, y que los gobernantes puedan encontrar en ellas el instrumento adecuado para llevar a cabo sus programas. Hay quien sostiene, como Michel Crozier, que lo que sucede es que hay una crisis universal de las Administraciones públicas que se manifiesta en que en ningún país su actividad es satisfactoria, hasta el punto de que pueda decirse que constituyen el eslabón débil de los sistemas sociales modernos. Piensa Crozier que los problemas son los mismos en todos los países aunque muchas veces reciban respuestas diferentes, y se resumen en que las relaciones que existen entre el Estado y la sociedad impiden que ésta reciba los servicios necesarios o de la manera oportuna. La razón de tal situación radicaría en que actualmente hay más necesidades y demandas de actuación pública que nunca, y a la vez más dificultades para intervenir derivadas de la complejidad que ha llegado a adquirir la tarea de administrar. En opinión de este autor lo que hay que hacer es ir a lo que llama un :Estado modeston: pero tal opción pertenece sin duda al reino de la discusión ideológica, por lo que no es cosa de entrar en ella en estas páginas.

Creo, sin embargo, que pueden decirse muchas cosas al respecto, reservando al lector la decisión de qué tamaño prefiere para las Administraciones públicas con las que ha de convivir (esto es, qué responsabilidades piensa que deben asumir). Y entre esas muchas cosas que pueden decirse están, sin duda, el carácter que deba atribuirse a las reformas que se emprendan, la evaluación de la eficacia y la eficiencia de la acción pública a través del análisis de políticas, y la práctica de algún control de calidad en los servicios prestados a los ciudadanos. Veamos sumariamente algunas reflexiones sobre aspectos muy básicos de las cuestiones mencionadas.

\section{Sobre distintas formas de entender la reforma de las Administraciones públicas}

Desde el final de la II Guerra Mundial hasta el comienzo de la década de los setenta, muchos países acometieron reformas de sus Administraciones públicas con mayor o menor éxito. Pero a partir de la crisis económica las cosas parecen haber cambiado, hasta el punto de que puede sin duda hablarse de un necesario replanteamiento en las estrategias para la reforma de la Administración. Ello parece especialmente evidente en el caso de aquellos países que a la altura de 1970 habían alcanzado un nivel de desarrollo económico, social y político que permitía hablar de ellos como de Welfare States: es justamente tal condición, y su pregonada crisis, lo que implica la necesidad de una profunda revisión del modelo tradicional de reforma de la Administración. En efecto, si en los procesos clásicos de reforma tanto las estructuras organizativas como los esquemas de adopción de decisiones y las pautas conductuales establecidas habían tendido siempre a resistir el cambio, mucho más cuando las dimensiones y la complejidad de las Administraciones propias del Welfare State constituyen un importante obstáculo adicional a los propósitos de reforma, y dotan además de una especial inercia a la maquinaria administrativa; todo ello, hoy día, en un contexto de fuertes demandas generalizadas de los bienes y servicios prestados a los ciudadanos por las Administraciones públicas. Tanto más se aproxima un Estado a lo que entendemos por aEstado de bienestarn, su Administración se hace más grande, más compleja, más costosa, más difícil de manejar. No comparto en modo alguno la tesis de que esos Estados asu- 
men una «sobrecargan no justificada de responsabilidades políticas y sociales que les lleva necesariamente a la crisis fiscal y al colapso burocrático, pero es claro que sus Administraciones se sitúan en un orden de magnitud y complejidad que no tiene nada que ver con la Administración anterior a la mitad del siglo, ni con cualquier otra gran organización existente en el sector privado de la economía. Piénsese, por poner un ejemplo, que sólo en el sector de la educación pública trabaja actualmente en nuestro país casi medio millón de personas, dependientes de las distintas Administraciones, y algo menos, pero casi otro tanto, en el de la salud pública.

Un factor más, digno de ser subrayado, es que la mencionada complejidad de las "Administraciones para el bienestar" hace que el grado de interdependencia entre los distintos segmentos que las integran sea extraordinariamente grande, con lo que la modificación o el tratamiento aislado de cualquier elemento es virtualmente imposible. Los efectos de las medidas adoptadas en no importa qué sector, organización o proceso afectan a ámbitos mucho más amplios, y producen con frecuencia efectos perversos (no queridos o, al menos, no previstos) que hacen mucho más difícil el planteamiento racional de cualquier programa de reforma. De otro lado, la mayor complejidad implica un mayor nivel de diferenciación, con lo que las grandes organizaciones públicas son realmente constelaciones de fragmentos de difícil coordinación e impensable reducción a unidad, con especificidades culturales muy marcadas y ámbitos de regulación inconmensurables.

Careceria de sentido, desde esta situación, añorar una mítica "buena y vieja Administración" de tiempos pasados, abarcable e inteligible: del mismo modo sería absurdo volverse hacia las reformas administrativas clásicas para encontrar inspiración y soluciones a los problemas actuales de las Administraciones públicas. Y entre otras cosas porque no se trata sólo de que éstas hayan visto aumentar su tamaño, complejidad, diferenciación e interdependencia, sino que han sufrido una profunda modificación de su papel: alguien ha dicho que han dejado de ser organizaciones dependientes para convertirse en instituciones relativamente autónomas.

En efecto, la mayor parte de las Administraciones públicas son hoy en día capaces de controlar ciertos aspectos de su entorno, con frecuencia crean y manipulan su propia clientela, tienen aliados y enemigos, pactan con los grupos de interés, se atreven en ocasiones a desarrollar presiones políticas sobre gobernantes y legisladores, mantienen accesos privilegiados a la prensa e incluso sus propios periodistas a sueldo, etcétera. Los distintos sectores sociales cuentan con ellas de una forma u otra, y todo el mundo tiene expectativas compartidas respecto de sus modos de comportamiento, más o menos establecidos (y no sólo jurídicamente regulados); de suerte que la perspectiva de su eventual reforma, o ausencia de reforma, moviliza un gran volumen de intereses: internos (de la organización) y externos (propios de su clientela). Por otra parte, esas grandes organizaciones públicas anstitucionalizadas" tienden por su propia naturaleza a sufrir una cierta inercia, conservadurismo y rigidez, apareciendo con frecuencia como lentas y rutinarias y, por ello mismo, como necesitadas de reforma y -a la vez-difícilmente reformables (al menos utilizando el modelo clásico). .

Pero se diría que con los anteriores argumentos se está incurriendo en una cierta reificación de esas *Administraciones para el bienestar: nada más lejos de mi propósito, ya que, pese a su indudable proceso de institucionalización, están dirigidas por políticos y servidas por funcionarios, que en su actuación responden a propósitos definidos e identificables. Claro está que todas las organizaciones, una vez creadas y en funcionamiento, adquieren una suerte de vida propia, que no es sino expresión de los intereses que se anudan en ellas y en su entorno: es bien sabido que las construcciones sociales suelen escapar en mayor o menor medida al control de sus creadores. Con todo, sin embargo, resulta esencial examinar el papel desempeñado en las Administraciones públicas por sus responsables y servidores.

Las peculiares características de las Administraciones públicas en el Estado de bienestar han venido a agudizar los tradicionales problemas de ajuste entre los respectivos papeles de políticos (elegidos o designados para el cargo) y funcionarios (esto es, administradores profesionales de carrera). Tales problemas constituyen un tema recurrente en la Ciencia política, y suelen plantearse - como en el caso de WEBER - en términos de la posible debilidad de la posición de los political appointees frente a la de los altos funcionarios profesionales, expertos en el ramo de que se trate y en el funcionamiento de la correspondiente maquinaria administrativa. Es notorio que los "altos cargos" de nombramiento político no siempre se sienten cómodos con sus subordinados profesionales, no tanto por suponerlos políticamente desleales (esto es, afines a un partido diferente del que está en el Gobierno o, en casos de coalición, a aquel al que pertenece el "alto cargo"), sino más bien por suponerlos vinculados a unas tradiciones de la casa que pueden ir desde meros modos de actuar, pasando por intereses profesionales de los propios funcionarios, hasta intereses de las "clientelas" del ramo de que se trate, que pueden dificultar la gestión del aalto cargon o el logro de los objetivos propuestos.

Hay que tener en cuenta que si el papel desempeñado por los altos funcionarios ha consistido alguna vez en la mera ejecución instrumental de las medidas decididas por los políticos, no sucede desde luego así en las extremadamente complejas Administraciones actuales. Piénsese, por ejemplo, en que difícilmente tales medidas pueden ser decididas en todos sus detalles técnicos por los órganos políticos que dirigen las distintas Administraciones públicas, ni siquiera con la eventual asistencia de sus Gabinetes (constituidos por personas que no precisan tener la condición de 
funcionarios de carrera, y sí la confianza profesional y política del -alto cargo. de que se trate); de suerte que el propio diseño e instrumentación de las medidas o policies implica normalmente una cuota más o menos grande de discrecionalidad encomendada a los funcionarios, que éstos ejercen en su condición de expertos. De hecho, y cuando los objetivos políticamente fijados son muy generales o relativamente poco concretos, la colaboración y asistencia de los funcionarios profesionales, incluso en la selección y fijación de las policies, resulta imprescindible. Si a esto se añade que con frecuencia los objetivos de la acción pública no pueden modificarse de un día para otro, y que buena parte de las medidas requieren períodos de tiempo relativamente largos para su ejecución, no es de extrañar que a veces los políticos nombrados para un cargo tengan una sensación de impotencia frente a un ámbito de actuación en el que todo puede parecer decidido $y$, más aún, en el que todo parece estar en manos de los funcionarios ade la casa.

Por su parte, los funcionarios se sienten recelosos de quienes son nombrados para cargos de designación política con poca o ninguna experiencia al respecto, temiendo las discontinuidades que puedan producirse (bien en las pautas establecidas, bien en la prestación del servicio de que se trate). No es raro que el recelo sea mutuo, por suponer el "alto cargo" que habrá de contar con probables reticencias frente a sus innovaciones. Incluso a veces (en los países en donde ello es posible), los políticos recién designados para el cargo hacen uso de la libre designación para sustituir a los funcionarios de mayor nivel por otros, también funcionarios, pero cuya lealtad política o personal ofrezca una mayor confianza al nuevo "alto cargo": esta técnica, que en otro lugar he calificado como "spoils system entre funcionarios", implica en mi opinión un anacronismo en relación con la profesionalidad que constituye desde hace alrededor de un siglo una de las características de la función pública moderna, y un riesgo para la continuidad de los servicios en supuestos de alternancia política. Adviértase, por otra parte, que de la misma manera que los political apointees son responsables frente a quienes los han designado y -al menos los de más alto nivel-frente a la opinión pública, los funcionarios -y no sólo los altos- son responsables de hecho frente al público que diariamente entra en contacto con la Administración, sea a través de las "ventanillas", sea en la entrega y recepción de toda clase de bienes y servicios. Las protestas y quejas cotidianas de los ciudadanos las reciben en un Hospital los enfermeros y los médicos, no el Director General de Hospitales, el Subsecretario de Sanidad o el Ministro de Salud Pública. Quien "da la cara" a diario por las bibliotecas son los bibliotecarios.

Consecuentemente, si siempre ha sido una frontera problemática la que articula el Gobierno y sus "cargos políticos" con la Administración y sus funcionarios, hoy lo es mucho más, hasta el punto de que a veces se requiera más bién una ureforma de la
Gobernación. que una reforma de la Administración, en el sentido de que se perfeccione la capacidad del poder politico para utilizar de manera adecuada la enorme potencialidad del aparato del Estado y, en general, de los muchos organismos administrativos disponibles en el sector público de la economía, por decirlo en los términos más amplios posibles. En todo caso, el papel institucional de dichos aparatos ha de ser instrumental para cualquier Gobierno democráticamente elegido; instrumentalidad que implica eficacia (logro de los objetivos propuestos) y eficiencia (al costo adecuado, y en todo caso al más bajo posible). De aquí la necesidad de la reforma $\multimap$ las reformas- de la Administración.

Pero las reformas clásicas fueron llevadas a cabo cuando el ritmo de cambio social era más lento, la sociedad estaba menos organizada y era menos compleja, y la tecnología más asequible y simple. Los sistemas administrativos eran más fáciles de comprender, sus deficiencias más obvias, y lo que había de ser cambiado más evidente: todo lo que se necesitaba era tomar la decisión de cambiarlo. No será necesario insistir en que las Administraciones públicas actuales son cuantitativa y cualitativamente diferentes: la acción pública es mucho más extensa y ambiciosa, afecta a procesos sociales de mayor importancia crítica y estratégica, y se lleva a cabo actualmente en un mundo mucho más complicado caracterizado por la incertidumbre, la inestabilidad, e incluso la turbulencia. Todo ha cambiado y está cambiando de tamaño, orientación, función y técnica en diferentes formas y velocidades. Puede decirse que nada es ya seguro, cuando muchas cosas lo eran, o parecían serlo, en la fase anterior: aunque en ella se salía de una devastadora guerra mundial y se planteaban toda suerte de enormes problemas políticos, económicos y sociales, ello sucedía, pese a todo, en un mundo menos complicado que el actual.

La actual incertidumbre afecta también, en mi opinión, a los propios estudios sobre Administración pública y sobre su reforma, que hace no más de treinta años eran simples, claros y prácticamente sin alternativas; hoy, en cambio, son complejos y dubitativos, ofreciendo una gama de posibilidades que hace difícil identificar políticas de utilización inmediata que puedan ser adoptadas de manera más o menos unilateral por órganos de alto nivel. Lo que no es más que un reflejo de la pérdida de la inocencia respecto del papel de la acción pública en el mundo actual. En efecto, el optimismo con que no hace muchos años se pensaba que el Welfare State resolvería todos los problemas sociales ha dado paso a actitudes más cautelosas en el mejor de los casos. Hasta los más partidarios de que el sector público asuma las responsabilidades que sean necesarias para garantizar el bienestar de la población se muestran hoy preocupados por las dimensiones, la complejidad y los problemas del Big Government. Por otra parte, muchos de tales problemas son políticos, y ya nadie cree que los problemas políticos puedan 
resolverse con soluciones administrativas más o menos tecnocráticas. En todo caso, el enorme volumen de servicios de bienestar y de organismos dedicados a su prestación se desliza fácilmente por las vías de la inercia, de la rigidez organizacional, de la crisis fiscal y del déficit público.

Dejando aparte las posiciones neoliberales que tratan de desmontar o erosionar el Estado de bienestar y de poner límites a las políticas socialdemócratas, abogando por la privatización de servicios y por la desregulación en favor de un mercado que se identifica demasiado rápidamente con la sociedad civil, a veces las reacciones contra el actual estado de cosas toman el atajo de denigrar a los políticos o a los funcionarios (que a veces incluso se denigran mutuamente) como si fuesen los culpables de la nueva complejidad. De hecho, lo que en este terreno puede reprocharse a los políticos es atribuir a las cuestiones de administración un grado muy bajo de prioridad, de suerte que raramente las atienden y, cuando lo hacen, suele ser de manera bastante simplista y pagando un excesivo tributo a las más mostrencas ideologías acerca del mal funcionamiento de la maquinaria administrativa. Los funcionarios, por su parte, pueden tender a compensar la velocidad y profundidad del cambio social reforzando la continuidad y estabilidad de la acción pública, con lo que, si bien en ocasiones prestan un estimable servicio, también favorecen la tendencia al desarrollo de factores de inercia, aun cuando se empeñen más frecuentemente de lo que se piensa en mejorar la eficacia de la Administración.

Durante los años en que se estableció y desarrolló el Estado de bienestar, el Estado asumió la creación y expansión de servicios públicos, poniendo su administración bajo la responsabilidad de funcionarios profesionales, financiando dichos servicios con cargo al Presupuesto (o, en todo caso, a tesorerías públicas), y sujetándolos en lo posible a controles políticos y técnicos estandarizados y centralizados. Hoy día, en cambio, todo el mundo clama por la descentralización y la desconcentración, por la desburocratización e incluso por la desregulación: se diría que las anheladas reformas tratan de romper con toda una manera de entender el papel del Estado y sus relaciones con la sociedad civil que ha estado vigente desde la mitad del presente siglo hasta hace pocos años.

El cambio ha sido, pues, también cultural (en los valores, normas, símbolos e ideologías), por lo que cualquier reforma de la Administración habrá de tener en cuenta tal fenómeno. Baste un ejemplo: las reformas clásicas tendieron a actuar sobre aspectos institucionales (normas jurídicas, procedimientos reglados, estructuras orgánicas, régimen de los funcionarios, requisitos formales, etcétera), y los instrumentos para el caso se centraron en las reorganizaciones, en la mecanización de procesos, en la racionalización de los métodos de trabajo y en la modificación de las normas aplicables. Pero hoy en día el punto de vista que se supone ha de primar en la reflexión crítica sobre la Administración pública no es el del gobernante, sino el de los gobernados en tanto que destinatarios o eclientes" de la acción pública. Dicho con más precisión: en el amplísimo campo de la acción pública goza hoy de prioridad la producción y entrega de bienes y servicios a los ciudadanos, y para su mejora se estima que la perspectiva a utilizar no es la de quienes dirigen el proceso (que ha sido la tradicional), sino la de los usuarios finales de dichos bienes y servicios.

Una experiencia típica de cualquier reforma es que las estructuras orgánicas, los procesos de adopción de decisiones y las pautas conductuales en ellos implicadas son bastante refractarias a los cambios esperados (lo que SelzNick llamaba "la recalcitrancia de los instrumentos"), con lo que la evaluación constante de los resultados de la reforma, especialmente sobre los outputs del proceso, se convierte en un elemento esencial de la misma: y hay que reconocer que ello ha recibido muy escasa atención en las reformas clásicas.

En todo caso, la reforma de la Administración se entiende actualmente como centrada en la respuesta del Gobierno y de la maquinaria administrativa a las presiones sociales externas, pero sin perder de vista el papel del Estado en la remodelación de la sociedad y en la orientación y control de la política económica y social. Quiero decir que la generalización de la "perspectiva del cliente" no debe reducir el diseño de la acción pública a un mero juego adaptativo del tipo estímulo-respuesta, ya que las responsabilidades públicas no se agotan en la entrega de bienes y servicios de apropiación individual o incluso colectiva. Pero no es el momento de abordar estas grandes cuestiones, y sí sólo de hacer constar que en la reforma de las Administraciones públicas se pone hoy el acento en las medidas destinadas a incidir directamente en los resultados de la actividad pública, no en la mera actividad, con lo que se tiene primordialmente en cuenta el punto de vista de los ciudadanos, que no están inmediatamente interesados en el tipo de reformas propio de la fase anterior (básicamente las estructurales y funcionariales), sino en lo que cada día reciben de la Administración.

Por último, las reformas administrativas actuales se producen en un escenario de crisis fiscal del Estado más o menos intensa, en el que la limitación del crecimiento de los gastos públicos (por no hablar de su reducción) y el mantenimiento del nivel de los servicios prestados (por no hablar de su mejora) se presentan como requerimientos necesarios y relativamente incompatibles, que generan estrategias de reforma dirigidas al aumento de la productividad de las organizaciones públicas, lo que exige una cuidadosa y permanente evaluación de los resultados de la acción pública.

La reforma, pues, es cada vez más difícil, y desde luego hoy mucho más que antes. Ciertamente, nunca ha sido fácil; pero una vez que se llevaron a cabo las grandes reformas clásicas que per- 
mitieron la generalización del Estado de bienestar, las Administraciones públicas consiguieron alcanzar un nivel de funcionamiento bastante aceptable (llegando a eprocesar. muchas de ellas prácticamente la mitad del PIB de sus respectivos países, sin colapsos ni irremediables cuellos de botella dignos de mención). Pues bien, este aceptable funcionamiento parece a algún autor una dificultad a vencer cuando se trata de abordar nuevas reformas, que no parecen ya tan importantes y urgentes como las que en su dia se acometieron, por lo que, ante sus dificultades, no acaban de recibir el necesario apoyo político. Y sin embargo la (relativa) crisis del Welfare State, la ineficacia o ineficiencia de ciertos servicios y prestaciones masivas, la evolución prácticamente irreductible de los gastos públicos, etcétera, imponen la necesidad de continuar pensando en términos de mejora, reforma o modernización de las Administraciones públicas.

Bien es verdad que el propósito de reformar la maquinaria de la acción pública no reviste ahora las características que le confirieron su peculiar fisonomía en la etapa anterior: ni la misma noción de reforma, ni sus principios y métodos, ni sus estrategias, parecen haber resistido la prueba de la crisis de los años setenta. Desde luego, la noción de reforma se ha transformado profundamente, pues ha pasado de ser un evento excepcional y aislado del que queda memoria histórica a convertirse en una tarea cotidiana: la Administración no ha de reformarse una vez cada generación, o en lapsos de tiempo incluso más dilatados, sino que es algo a lo que debe prestarse atención constantemente, sin solución de continuidad. Podría quizá pensarse que esta transformación de la noción de reforma implica una suerte de trivialización que ha de restar necesariamente fuerza a sus propósitos, pero el argumento contrario parece tener más peso: la reforma solemne y esporádica parece condenada a un alto riesgo de banalización de sus contenidos y efectos y a una fuerte frustración de expectativas, toda vez que cumplido el proceso reformador las cosas son abandonadas a su propia dinámica, que implica sin duda un fuerte componente esperable de rutinización. Hoy goza de una amplia aceptación la idea de que en lugar de una reforma de la Administración hay que instrumentar un clima de reajuste permanente, en el sentido de establecer las condiciones necesarias para su corrección y adaptación a unas circunstancias cambiantes de manera sistemática y cotidiana. Más que de reforma, pues, se hace necesario hablar de reformas.

Por otra parte, los principios y métodos ofrecidos tradicionalmente por la Ciencia de la Administración para los programas de reforma se revelan hoy día como poco adecuados; como algún autor ha señalado, tales principios frecuentemente ignoran toda alternativa, así como la necesidad de operar rectificaciones en el curso de la acción a través del necesario feedback, e incluyen propuestas irrealizables e incluso medidas contraproducentes. De otro lado, la estrategia tradicional para la reforma consistía en imponer adesde fuera" una serie de me- didas a organizaciones reluctantes y poco dispuestas espontáneamente a asumirlas, organizaciones que eran tratadas como meros elementos mecánicos respecto de los que se había formulado la decisión de que necesitaban determinados cambios para mejorar su rendimiento. Pues bien, el planteamiento hoy en día es muy diferente: se sostiene, por ejemplo, la necesidad de sustituir siempre que sea posible la reforma impuesta desde fuera por una suerte de autorreforma (lo que CAIDEN ha denominado proceso de revitalización). Las distintas organizaciones que componen una Administración asumen la responsabilidad de autorreformarse, y lo hacen por su propia iniciativa y de manera continua a través de una task force dedicada precisamente a ello, entre cuyas tareas principales están, por una parte, producir una importante cantidad de información, negociación y compromiso con los funcionarios y empleados de la organización y, por otra, estimular sistemáticamente al público que recibe los bienes o servicios que ofrece la organización a manifestar las quejas que provocan sus fallos y a expresar lo que sería a su juicio un servicio deseable.

Pero la insuficiencia actual de los planteamientos clásicos no hace descabellado o imposible el propósito de reformar la Administración, que sigue siendo tanto más necesario cuanto que las demandas de la sociedad así lo exigen. Lo que se impone en la nueva situación es prestar una atención más cuidadosa al concepto mismo de reforma, a sus principios y a las estrategias a utilizar, y calcular mejor las condiciones de éxito, así como sus seguras limitaciones, a partir de un análisis más realista del contexto político y de la propia Administración de que en cada caso se trate.

Por lo que se refiere al contenido de la reforma, el cambio desde el que he llamado modelo clásico hasta las prácticas actuales es digno de ser destacado. La reforma de la Administración ha sido tradicionalmente una cuestión limitada a alterar el estatuto jurídico general del aparato del Estado o de las Administraciones locales, modificando los derechos y garantías de los particulares en el sentido de otorgarles una mayor protección, de manera que se sujetase más rigurosamente al imperio de la Ley el conjunto de la acción pública; se trataba, por tanto, en este tipo de reformas de perfeccionar el Derecho que regula la actuación de las Administraciones públicas y sus relaciones con los ciudadanos. Además de estos propósitos generales, las reformas clásicas se ocupaban de las organizaciones administrativas propiamente dichas bajo la forma de un aasunto interno* decidido e impulsado adesde arriba" con el propósito -en el mejor de los casos- de mejorar la eficiencia (esto es, de incrementar la productividad mejorando la relación entre los recursos empleados y los logros obtenidos). Tal managerial approach, como ha sido llamado, escasamente conectado con el entorno, venía a instrumentarse la mayor parte de las veces como una mera modificación de las regulaciones internas en términos de reorganización (sobre todo para dividir competencias, haciendo más frondoso el organigra- 
ma), de variación de las normas reguladoras del estatuto de los recursos humanos utilizados, y de cambio de los procedimientos tramitatorios o de control (centrándose, sobre todo, en los aactos administrativosn destinados a producir efectos jurídicos relevantes para terceros, y en el control de contrataciones, ingresos y gastos).

No sería exagerado decir que hoy se tiene una visión bastante diferente de lo que ha de ser una reforma de la Administración: el buen diseño y la racionalidad interna del aparato no constituye ya el objetivo primordial de la reforma, y ni siquiera la mejora de su productividad. La reforma de la Administración no suele definirse actualmente en términos de los cambios internos que hubieren de introducirse en la estructura y el funcionamiento de las organizaciones públicas, sino en términos de los cambios que han de llevarse a cabo para que la acción pública logre los objetivos fijados por el respectivo Gobierno, de suerte que satisfaga las demandas y requerimientos del entorno social, económico y político. No quiere esto decir que se considere irrelevante la protección de los derechos de los ciudadanos, la racionalidad del diseño orgánico y procedimental, o el control de legalidad de gastos y pagos, sino que actualmente todo ello se da por descontado y su progresivo perfeccionamiento se considera más o menos institucionalizado, de suerte que el énfasis se desplaza a otro plano completamente diferente: el de la frontera que separa las Administraciones de su entorno social.

Así pues, la reforma de la Administración es actualmente bastante más que reorganización administrativa o mejora de procedimientos, medidas que han producido en todas partes resultados decepcionantes a causa de que dichos cambios de estructuras y procesos se trataban como fines en sí mismos, con independencia de sus contenidos y de los objetivos a que servían. Claro está que tal decepción se produce desde una determinada óptica: la de los usuarios de los servicios y beneficiarios de los bienes públicos, que no están directamente interesados en las innovaciones estructurales: lo que les interesa es que la Administración ponga efectivamente a su disposición, y de la manera adecuada, los bienes y servicios a que tengan derecho. Como beneficiarios de la acción pública ven a la Administración desde un punto de vista completamente diferente al de los dirigentes públicos: la ven de abajo arriba, por así decirlo, y frecuentemente con una desagradable sensación de alienación e impotencia y con una inmediata percepción de sus deficiencias. De ahí que en la nueva sensibilidad acerca de la reforma de la Administración haya ido tomando cuerpo una orientación hacia lo que podríamos llamar innovación en la prestación, que se preocupa ante todo de la entrega al público de los bienes y servicios debidos y del contenido práctico de tales servicios. Esta perspectiva está, pues, más atenta a las demandas externas que a los problemas internos, y más dispuesta a considerar que la Administración está al servicio de los ciudadanos que al servicio del Estado.
No creo que pueda decirse que con estos nuevos planteamientos se trata de rechazar u olvidar la orientación que, articulada con el cambio en las normas jurídicas, han suministrado a las reformas administrativas durante muchos años tanto la aorganización científica del trabajo" como la llamada escuela de las relaciones humanas", habitualmente presentes en la innovación estructural tradicional. Lo que sí sucede, en mi opinión, es que tal orientación ha ido cediendo terreno en favor de la calidad y cantidad de los bienes y servicios entregados a los ciudadanos por las Administraciones públicas. No es que se rechacen las medidas estructurales y procesales de las reformas clásicas, sino que se piensan que su única justificación radica en que estén directa y explícitamente dirigidas a procurar a los ciudadanos más y mejores bienes y servicios. Se concibe así a los ciudadanos como "usuarios finales" del sistema político-administrativo, y son precisamente esas prestaciones finales las que justifican la existencia de la mayor parte de las organizaciones públicas, y las que se constituyen en eje del empeño reformista.

Es cierto, desde luego, que actualmente el interés de los expertos se centra en los momentos previos y posteriores a los que constituian el objetivo de los reformadores clásicos: los problemas de la implementacion por una parte, y el análisis de los resultados de las políticas por otra, ocupan sin duda el primer plano de la literatura científica y aplicada desde hace algunos años.

La cuestión de la implementación de políticas (su diseño, cálculo de viabilidad, previsión de costes directos e indirectos, asignación de recursos, control de resistencias, calendario, procedimiento, etc.), así como la del análisis de políticas (determinación de la eficacia o medición de logros, cálculo de la eficiencia o comparación de costos y resultados, análisis de costo/ beneficio, examen de las consecuencias no previstas o no queridas, rectificación del diseño a la vista de los resultados, etc.), constituyen, como digo, los capítulos más importantes en que insisten las corrientes actuales de reforma de las Administraciones públicas, con una tradición ya bastante larga en determinados países, sobre todo por lo que se refiere al policy analysis.

Se observará que se trata, como he indicado, de una orientación que centra la reforma en los momentos previos y posteriores al funcionamiento instrumental y general de la maquinaria administrativa, que es tratada desde esta perspectiva como una suerte de "caja negra", alimentada con el diseño y los recursos de un proyecto que se propone objetivos específicos, y que produce unos determinados resultados. La tesis de que tales resultados son lo que verdaderamente importa es lo que ha desplazado la atención desde el managerial approach de las reformas administrativas clásicas, con su insistencia en la innovación estructural y en la regulación jurídica, a la preocupación por la street level bureaucracy orientada a la innovación en la prestación, esto es, a optimizar la cantidad, calidad y oportunidad de los bienes y 
servicios entregados a los ciudadanos. Se trata, podría decirse, de un desplazamiento paralelo al que va de la calta. a la baja politica. (en palabras de Rose), y quizá al producido del utopismo tecnocrático taylorista al fordismo economicista y pragmático.

Y, claro está, no hay que ser misoneísta respecto de estos nuevos enfoques y prácticas, pero tampoco hay que considerarlos como una panacea que venga a resolver brillantemente y para siempre las limitaciones de las organizaciones públicas. Ni toda la acción pública es reductible a programas para el logro de objetivos definibles en términos de unidades que puedan contarse o medirse (como ya puso en su día de manifiesto la decepción sufrida en muchos países con el famoso Presupuesto por Programas, ingenuamente valorado como solución universal cuando es sólo un instrumento para determinados propósitos, pero inútil para otros), ni toda la cuestión se reduce al análisis previo y posterior al curso instrumental de la acción pública. Hay que convenir en que dicho tipo de análisis es imprescindjble, pero también en que lo que sucede en el interior de la «caja negran (lo que preocupaba a los reformadores clásicos) sigue siendo de importancia crítica, como revela la frustrante experiencia de tantos directores de organismos públicos que se ven compelidos a consumir su tiempo y energías tratando de resolver problemas de personal y de justificación y tramitación de gastos y pagos, perdiendo de vista sus objetivos y la preocupación por los resultados de su actuación.

Por consiguiente, en buena hora se ocupe la reforma de la Administración de los problemas de la implementación de programas y del análisis de sus resultados; pero ello no debe evitar que continúe prestando atención a los problemas tradicionales, ya que ni están resueltos ni quizá puedan estarlo definitivamente. Lo que los nuevos enfoques ofrecen es, me parece, más instrumentos (e instrumentos nuevos) para luchar contra la inercia social de las Administraciones públicas: por lo que han de ser bienvenidos, con clara conciencia tanto de su urgencia como de sus limitaciones. Y ello sin olvidar que toda reforma ha de partir de un conocimiento profundo, detallado y contrastado empíricamente de la realidad que se pretende reformar (obviedad de la que no siempre son lo bastante conscientes los arbitristas potenciales), así como que no cabe aquí la mera importación en unos países de recetas o medidas utilizadas con provecho en otros, aunque sí de los nuevos enfoques que puedan contribuir a renovar y ampliar los instrumentos teóricos disponibles para el diseño de las reformas.

Por lo que hace a nuestro país, baste una breve referencia: a lo largo del proceso de transición a la democracia se puso repetidamente de manifiesto que la reforma de la Administración que había tenido lugar en España entre 1957 y 1965 (la llamada "reforma tecnocrátican) hacía ya largo tiempo que había agotado totalmente sus efectos, además de que la crisis social y política de los últimos años del franquismo había repercutido de manera negativa en el funcionamiento del aparato burocrático. Por tanto, con ocasión de las elecciones de 1982 los partidos políticos que concurrieron a ellas prestaron en sus programas más atención de la que hasta ese momento había sido habitual a la necesidad de reformar la Administración, de modo que cuando se formó el primer Gobierno socialista existía la expectativa, ampliamente compartida incluso por los propios funcionarios, de que iba a llevarse a cabo una reforma más o menos profunda. El Gobierno publicó pronto unas •medidas urgentes que no abordaban la reforma esperada, y tras algunas actuaciones sobre horarios de las oficinas públicas, atención a los ciudadanos e incompatibilidades de los funcionarios, hubo que esperar hasta 1984 la promulgación de una Ley para la reforma de la función pública, de carácter limitado aunque de efectos importantes (en los que no es del caso entrar ahora). No llegó, pues, a acometerse formalmente ninguna reforma global, de corte clásico, de la Administración del Estado, si bien estaba teniendo lugar una transformación profundísima del aparato español para la acción pública a través de la puesta en marcha de las Administraciones autonómicas, que rompían con una tradición centralista secular: pero curiosamente dicha transformación no ha sido percibida como reforma, pese a serlo de manera indudable. Administraciones autonómicas aparte, no es del caso reseñar aquí las muchas medidas de todo tipo adoptadas por los sucesivos Gobiernos desde 1982, pero sí hay que destacar la explícita renuncia a instrumentar reformas clásicas y la aprobación en su lugar de un Plan de Modernización de la Administración del Estado, con dos fases: la primera en 1992, con 204 proyectos de los que según información oficial se ha logrado un 70 por 100 de cumplimiento, y la segunda en 1994, con 165 proyectos en los que se procura, sobre todo, reducir el gasto y aumentar la calidad de los servicios. Se han preferido, pues, los cambios concretos y limitados a las grandes reformas, orientados hacia "un proceso permanente de adaptación" y vinculados al proceso de modernización del conjunto de la sociedad españolan. Las críticas que dicho Plan ha recibido apuntan a la trivialidad de gran parte de los cambios propuestos, que contrasta con la solemnidad de su preparación y de su presentación a la opinión pública. Pero en todo caso hay que insistir en que la opción por la "modernización" (o conjunto de reformas limitadas) frente a la "reforma" simultánea y más o menos radical de todas las dimensiones administrativas es, sin duda, un signo de los tiempos.

\section{La eficacia y la eficiencia de las Administraciones públicas}

Hablar de eficacia y de eficiencia de las Administraciones públicas implica tomar en consideración los resultados o efectos de la acción pública, sobre todo desde un punto de vista 
cuantitativo (lo que no excluye, claro está, la apreciación de la calidad del producto). El interés por tales cuestiones es relativamente nuevo en nuestra tradición político-administrativa, en la que primaba la preocupación por la actividad más que por los resultados obtenidos, y siempre más la regularidad formal o jurídica del procedimiento que cualquier otra consideración. Hoy en cambio va siendo corriente el preguntarse por los resultados de la actividad, y la medida en que dichos resultados cumplen los objetivos pretendidos por el órgano que decidió la política de que se trate. Preguntas que no son fáciles de responder, no sólo por su escasa tradición, sino porque en el sector público de la economía no abundan los indicadores que con una razonable fiabilidad puedan ofrecer una información análoga a la que para las empresas privadas ofrece, por ejemplo, una cuenta de resultados.

Sería un error suponer que en la base de la preocupación por la eficacia y la eficiencia públicas no hay otra cosa que ideología neoliberal extrapoladora de criterios empresariales al ámbito público: por el contrario, su fundamento teórico y su desarrollo técnico constituyen la consecuencia de una evolución propia, derivada de las características de la acción pública en el Estado de bienestar, y que gira alrededor de la noción de legitimidad. En efecto, para la legitimidad política es esencial la eficacia de la acción pública, lo que confiere la mayor importancia a los resultados o logros de dicha acción. No se trata, pues, de que las Administraciones públicas deban ajustarse al modelo económico de las empresas privadas, sino de subrayar que la legitimidad política descansa, al menos en una parte importante, en la capacidad real de la acción pública para satisfacer las necesidades y demandas sociales. Y tal capacidad ha de evaluarse tras una contrastación empírica y realista de la eficacia y la eficiencia de las Administraciones públicas.

La eficacia aprecia el grado en que se alcanzan los objetivos deseados o previstos (cuántos niños se han escolarizado, cuántos kilómetros de carretera se han construido, en cuántas décimas se ha conseguido frenar el incremento del IPC, etcétera). La eficiencia, por su parte, mide el coste de los objetivos logrados (la cuestión no es aquí cuántos kilómetros de carretera se han puesto en servicio, sino cuál ha sido el coste de cada uno de ellos, y qué valoración merece ese consumo de recursos). Indagar la eficacia y la eficiencia de la acción pública permite que se revisen las líneas de actividad en las que no se logren en una proporción razonable los objetivos propuestos, o en los que se consuma de forma injustificada un volumen excesivo de recursos: en último extremo, dineros públicos.

Por lo que se refiere a la medición de la eficacia, esto es, ver si se han alcanzado, y en qué medida, los objetivos propuestos, implica que hubiesen sido previamente establecidos de forma concreta e identificable, lo que no es frecuente, y en ocasiones ni siquiera posible. Hay programas de acción pública en los que la identificación a priori de los objetivos está perfectamente clara (como suele pasar con la construcción de carreteras, por ejemplo), pero en otros muchos casos los propósitos se definen de forma mucho más vaga, o como mera inercia o continuidad de lo existente. A veces tal situación es consecuencia de la dificultad de formular con más precisión el propósito (como sería el caso, por ejemplo, de un organismo dedicado a autorizar licencias de obras solicitadas por particulares), pero en muchas otras ocasiones la falta de definición de los objetivos es una deficiencia política corregible. En efecto, la inercia es una característica de las grandes organizaciones, en las que se dan por supuestos muchos extremos sobre los que nada parece exigir mayores precisiones: hay una necesidad a la que atender, una demanda conocida de cierta actividad pública al respecto, y se cuenta con una organización, unos funcionarios y unos recursos para satisfacerla. Con lo que la continuidad está asegurada.

Acerca de la eficiencia en la utilización de los recursos, es obvio que todo razonamiento al respecto ha de partir de la constatación previa de los resultados obtenidos, con los que se pondrá entonces en relación el conjunto de recursos consumidos en su logro para determinar si son los también previstos de antemano o, por lo menos, entran dentro de lo razonable. Porque, en efecto, no basta con que se logren los propósitos de la acción pública, sino que es preciso que se logren a un coste adecuado. Y ello no por las razones de competitividad que son propias del sector privado de la economía, sino porque el empleo de los recursos públicos ("medios escasos para usos alternativos") está sujeto a una racionalidad de asignación no sólo económica, sino política, según la cual debe maximizarse su eficiencia: si en el sector público la ineficiencia no viene sancionada por mayores precios, desviación de la demanda y pérdida del mercado (como sucede en el sector privado), implica en cambio no poder atender otros objetivos, pérdida de la confianza ciudadana o de la legitimidad política, aumento del déficit o endurecimiento de la crisis fiscal. Consecuencias todas ellas sumamente perniciosas para el Gobierno y para el propio sistema político.

Una última precisión, que puede parecer ociosa: quien fija los objetivos de la acción pública no es la Administración, sino el Parlamento y el Gobierno (o los órganos políticos equivalentes en los ámbitos autonómico y local). Con las limitaciones que la evidencia empírica pone de manifiesto, las Administraciones públicas desempeñan un papel instrumental o ejecutor de las decisiones adoptadas por las instancias políticas acerca de los objetivos de la acción pública, decisiones que se plasman en un Presupuesto que no es sino la expresión cifrada en términos monetarios del programa político que el Gobierno presenta para su aprobación al Parlamento. Las Administraciones públicas, pues, no deciden sobre el destino de los dineros públicos (aunque no pueda desconocerse su influencia en la fase 
técnica de preparación del Presupuesto). Lo que hacen es administrar esos recursos con un cierto margen de discrecionalidad, tanto más pequeño cuanto más precisa sea la definición de los propósitos de la instancia política. Lo que todo esto supone es que la Administración trabaja para conseguir unos objetivos con unos medios dados: será eficaz si los logra, y eficiente si lo hace empleando una cantidad proporcionada de recursos.

El conocimiento sobre la eficacia y la eficiencia de las Administraciones públicas se obtiene a través del llamado policy analysis, o análisis de políticas públicas, instrumento del que me ocupo en el epígrafe siguiente. Pero si la expresión en inglés sugiere una técnica no sólo novedosa, sino incluso misteriosa, de hecho la práctica del análisis de políticas se da de vez en cuando, bien que de manera no institucionalizada, y desde luego sin utilizar tal nombre. Piénsese, por ejemplo, en que cuando se reduce o eleva el tipo de interés se escrutan y miden cuidadosamente los efectos, queridos o no, favorables o perversos, de tal decisión. Pues bien, no otra cosa es en realidad el análisis de políticas públicas: examinar las consecuencias de las medidas adoptadas, compararlas con lo previsto, y evaluar sus costos. Y algunas cosas más, a las que convendrá referirse a continuación.

\section{El análisis de políticas públicas}

Para nombrar en castellano lo que en inglés se denomina policy analysis (que evidentemente no puede ser traducido por "análisis políticon) se suele decir "análisis de políticas", y en concreto de políticas públicas. No hay en España tradición al respecto, aunque sí quien lleva a cabo de manera habitual tal tipo de análisis, sobre todo en lo que se refiere a los efectos producidos por las distintas medidas que se adoptan en política económica. Lo que se echa de menos es una práctica sistemática, científica, de análisis de políticas públicas, que es precisamente lo que caracteriza la tradición anglosajona al respecto. En este tipo de análisis se considera que la multitud heterogénea de las actividades públicas se ordena en policies, para cada una de las cuales se destinan determinados recursos (normas, personas, dineros públicos) que son movilizados y dispuestos para obtener determinados resultados. El análisis en cuestión tiene un carácter instrumental, en cuanto que versa sobre medios y fines, concentrándose sobre todo en los resultados conseguidos, y ello con una orientación empírica (tanto cuantitativa como cualitativa). Queda dicho que el policy analysis no se hace cuestión de los objetivos o propósitos establecidos por las instancias políticas (objetivos que en la práctica se refieren a la noción de bienestar, concentrándose sobre todo en los resultados obtenidos gracias a las políticas desenvueltas en las áreas de sanidad, educación, vivienda, pensiones, etcétera). No se trata, sin embargo, de que se acepten los fines como dados e indiscutibles en una obsequiosa actitud hacia el poder constituido, sino de examinar en qué medida tales fines se cumplen y a qué precio.

En las sociedades actuales, la principal evidencia que los ciudadanos corrientes reciben de los Gobiernos centrales o locales consiste en los resultados, buenos o malos, de los programas de actuación acometidos: resultados que son puestos en relación tanto con los objetivos propuestos como con los recursos movilizados para su logro. E incluso ha de tomarse en consideración, según creo, el grado en que la distribución del output de que se trate sea equitativa, examinando su eficacia ecualizadora.

Pero las cosas son más complicadas, en la medida en que no siempre los objetivos y recursos de un programa de acción pública han sido establecidos de manera exhaustiva y precisa, lo que dificulta o hace imposible la identificación del propósito o la política propuesta y el posterior análisis de los resultados obtenidos (¿con qué se comparan? ¿cómo se evalúa el grado de éxito o de fracaso de la política en cuestión? ¿Con qué criterio se determina la eficiencia en el uso de los recursos consumidos?). No es necesario decir que la imprecisión en el establecimiento de los objetivos propuestos o en los recursos asignados a su logro son deficiencias imputables a los órganos de decisión política, no a los aparatos administrativos para la acción pública.

Convendrá apuntar que este modelo de análisis de políticas públicas llevado a cabo a posteriori viene siendo completado por otras indagaciones que se refieren a la viabilidad política de posibles proyectos cuya implementación aún no ha sido decidida: es claro que los políticos profesionales practican habitualmente ese tipo de análisis prospectivo, en el que cada proyecto es evaluado de antemano no sólo en sus propios méritos, sino en su viabilidad práctica, en sus consecuencias para la posición política del Gobierno, e incluso para la carrera política del promotor de las medidas de que se trate. Y lo que se está generalizando cada vez más en este campo es sustituir lo intuitivo y pragmático de la práctica al uso por lo reflexivo y analítico propio, en este caso, de la ciencia política. De modo que no puede ya concebirse el policy analysis como una indagación únicamente retrospectiva, sino también prospectiva; y no sólo como un conjunto de valoraciones cuantitativas de la eficacia y la eficiencia de la acción pública, o cualitativas en relación a la calidad del servicio prestado o del bien entregado, sino como un intento de establecer juicios técnicamente fundados referentes a la viabilidad política de los proyectos. En todo caso, lo que prima es el análisis frente a la intuición, lo concreto frente a la impresión global, lo empírico (sea cuantitativo o cualitativo) frente a lo especulativo. Y no cabe duda de que las ciencias sociales resultan imprescindibles para todo ello: para la formulación, implementación y evaluación de las políticas públicas. 
Pero volvamos a lo que me parece que es el punto básico del policy analysis: la identificación y evaluación de los resultados de las políticas públicas, tanto desde el punto de vista de la eficacia (¿qué se ha logrado?) como de la eficiencia (¿a qué costo?). Este empeño analítico se lleva a cabo desde una perspectiva que podríamos llamar "del ciudadano" o del "usuario final. de los bienes y servicios ofrecidos por los distintos aparatos para la acción pública. La difusión del Estado de Bienestar (tan discutido hoy como se quiera, pero irreversible en la mayor parte de sus dimensiones) ha desplazado el centro de gravedad, como dice Richard ROSE, a la "baja política" de ofrecer bienes y servicios cotidianos a los ciudadanos. Es en esta frontera final de la distribución de dichas prestaciones donde se sitúa el análisis de políticas públicas, no en el gran teatro central de la confrontación ideológica y de la aalta política.

Pues bien, una de las reformas más importantes que puede acometer una Administración pública hoy en día es procurar la institucionalización del análisis de políticas, incorporando de esa manera a su actuación el "principio de realidad" que pueden aportar las ciencias sociales (no sólo la economía) al logro de los objetivos políticamente propuestos, y con un consumo de recursos proporcionado. $Y$ no es necesario decir que tal institucionalización del análisis de políticas públicas se echa de menos en España.

\section{Los problemas de la prestación de servicios}

Las Administraciones públicas, se dice, ofrecen a los ciudadanos bienes y servicios; pero la importancia relativa de los primeros es cada vez menor, al menos en lo que se refiere a las mercancías que, en concurrencia o no con otras análogas ofrecidas por el sector privado de la economía, constituyen la actividad que los administrativistas llamaban adación de bienes al mercadon. Lo más relevante hoy en día es la producción de servicios, entendidos como prestaciones de utilidad o provecho que pretenden satisfacer necesidades de los consumidores o usuarios, en cuya producción predomina el factor trabajo. Hay que destacar que la noción de prestación introduce directamente en el concepto de servicio elementos cualitativos, ya que lo destacable aquí no es un objeto material, sino un proceso presidido por relaciones interpersonales: lo que implica, como es obvio, dificultades en la medición de dicho proceso, opaco a cualquier indagación cuantitativa. Por otra parte, las expectativas de calidad con que el consumidor o usuario accede a la prestación tienen que ver con una noción de satisfacción mucho más dificil de determinar que la que se dirige a los bienes materiales o mercancías.
Algún autor ha aducido como criterios de calidad para aplicar a la prestación de servicios los de la certidumbre de la prestación (que implica regularidad y adecuación a la demanda), la capacidad del personal que ha de prestar el servicio (que supone competencia profesional, presteza, e incluso cortesía en las relaciones que se entablan), la accesibilidad del servicio (tanto en términos de proximidad geográfica como de sencillez en el contacto), facilidad de comunicación (que implica información suficiente y en lenguaje comprensible), y conocimiento por el prestador de las expectativas del usuario (para que no queden frustradas inicialmente). De dicha, y parcial, enumeración se desprende que la satisfacción del consumidor de servicios descansa tanto en elementos propios del acto de la prestación como en el contenido mismo de ella, lo que pone de manifiesto la dificultad de la determinación de la calidad en la prestación de servicios, al menos en los personales (esto es, en los que existe una demanda divisible que participa en forma de relaciones interpersonales en el acto de la prestación). No siempre, pues, será coincidente la valoración objetiva de la calidad de la prestación con el grado de satisfacción del usuario, entre otras razones porque éste ha de recibir la prestación con un comportamiento adecuado a la obtención de los resultados previstos. El dogma de la soberanía del consumidor se complica, pues, aquí, ya que su participación implica cierta actividad, e incluso diligencia, para que el servicio alcance la calidad esperada (piénsese, por ejemplo, en la enseñanza y en la cooperación que requiere por parte de los estudiantes). Con lo que se plantea el problema de si en caso de conflicto han de prevalecer las previsiones del prestador o el grado de satisfacción del usuario. Y no será necesario insistir en que tratándose de servicios públicos de amplia cobertura, prestados o no en régimen de monopolio, la cuestión se torna aún más difícil.

Desde este punto de vista, con frecuencia se ha dudado de la calidad de los servicios prestados en régimen de monopolio, y por tanto de muchos de los que prestan las Administraciones públicas. No es éste lugar apropiado para entrar en discusión de tanto fuste, pero si es evidente la importancia política que tiene el grado de satisfacción de los usuarios de los servicios públicos, y cómo es inseparable de cualquier valoración de su calidad, por más que la demanda popular de mayor calidad de los servicios pueda ser insaciable: sin duda, cualquier servicio podría siempre ser de superior calidad, especialmente si lo paga otro, es decir, un organismo público, es decir, nadie. Y esta reflexión no trata, en modo alguno, de cuestionar la satisfacción de los usuarios como criterio de calidad de los servicios, sino de subrayar la elasticidad sin límites de la demanda de calidad, y las dificultades que plantea su imprescindible evaluación.

Con lo que en los servicios públicos no habrá que ocuparse sólo de apreciar su eficacia (en términos de unidades de cobertura o prestación efectivamente logradas) y su eficiencia (o el 
consumo de factores provocado por tales logros), sino también y sobre todo su calidad, bien se mida con arreglo a estándares objetivos del interés público apreciados por la Administración, bien se atienda al grado de satisfacción manifestado por los propios usuarios (indagado por la Administración, expresado por las asociaciones de consumidores y usuarios, o puesto de manifiesto por las reclamaciones y protestas recogidas por el propio organismo, la prensa, el Defensor del Pueblo, etc.).

Tiene por ello el mayor interés que a principios de 1996 el Consejo de Estado esté preparando un dictamen sobre un proyecto remitido por el Gobierno, según el cual se someterá a control de calidad a los servicios que presta la Administración del Estado, de suerte que el Ministerio para las Administraciones Públicas pueda presentar periódicamente a las Cortes el resultado de dicho control. De hecho tal cosa se viene llevando a cabo en algunos organismos concretos por un observatorio de calidad. radicado en el propio Ministerio (y posiblemente por las empresas cuyos trabajos de auditoría se contratan a veces por determinados orgamismos). Sin duda, el Centro de Investigaciones Sociológicas y las empresas de estudios de opinión podrán aportar también una valiosa información al respecto, imprescindible en tanto que refleje la imagen que la calidad de los servicios recibidos de las Administraciones públicas tiene para los ciudadanos; y aunque sea verdad que ningún Gobierno podrá satisfacer plenamente la insaciable demanda popular de calidad, no es menos cierto que sólo ese imposible esfuerzo dinamizará la acción pública más allá de la inercia y de la mediocridad de las prestaciones. Y no estará de más repetir que el bienestar que la acción pública pueda deparar a los ciudadanos a través de la entrega de bienes y servicios (y la satisfacción con la calidad de los mismos) es hoy en día la principal fuente, si no la única, de legitimidad política.

- Catedrático de Sociología. Universidad Autónoma de Madrid.

\section{Bibliografia}

De entre la gran cantidad de bibliografía disponible sobre los temas tratados en las páginas anteriores, se ha seleccionado aquí un número muy limitado de referencias, caracterizadas todas ellas por su utilidad y fácil accesibilidad.

Sobre las nuevas orientaciones acerca de la reforma de las Administraciones públicas puede verse el libro de L. Metcalfe y S. Richards, La modernización de la gestión pública, Instituto Nacional de Administración Pública, Madrid 1989, y también Politica y Sociedad, Revista de la Facultad de Ciencias Politicas y Sociología de la Universidad Complutense, cuyo $n^{2} 13$, de 1993, es monográfico sobre .Modernización de la Administración Pública. Puede consultarse una buena colección de trabajos que sigue teniendo actualidad en G.Caiden y H.Siedentopf, eds., Strategies for Administrative Reform, Lexington Books, Lexington 1982. El conocido libro de M.Crozier, Estado modesto, Estado moderno. Estrategia para el cambio (Fondo de Cultura Económica, México 1989) tiene una orientación minimalista. Y la revista Documentación Administrativa dedica el segundo volumen del $n^{2} 218-219$ a una amplia variedad de cuestiones relativas a la eficacia.

Por lo que se refiere a España, el Ministerio para las Administraciones Públicas dio a conocer en 1990 unas Reflexiones para la modernización de la Administración del Estado, continuadas por varias monografías sobre medidas o ámbilos determinados. También para España, una visión crítica muy penetrante en A.NıtTo, La organización del desgobierno, Ariel, Barcelona 1984. Por último, sobre reformas de la Administración espanoola pueden verse los trabajos de M.Bfitrán, .La Administración pública y los funcionarios (en S.Giner, comp., España: Sociedad y política, Espasa-Calpe, Madrid 1990, para la -reforma tecnocrática. y la etapa de la transición), y ·La reorganización de la estructura del Estado (1982-1993). (en el V Informe Sociologico sobre la situación social en España, FOESSA, Madrid 1994, vol.I). Las actitudes al respecto de los funcio- narios a finales de 1983, en el libro del mismo autor, Los funcionarios ante la reforma de la Administración, Centro de Investigaciones Sociológicas, Madrid 1985.

Para la perspectiva que considera a los ciudadanos como clientes de las Administraciones públicas puede verse un documento de la OCDE titulado la Administración al servicio del público (Ministerio para las Administraciones Públicas, Madrid 1991), así como los trabajos publicados en el no 1 de la revista Gestión y Análisis de Políticas Públicas, de sept.-dic. de 1994. Y pese a los aǹos transcurridos sigue teniendo gran interés el libro compilado por E.Katz y B.Danet, Bureaucracy and the Public. A Reader in Official-Client Relations, Basic Books, Nueva York 1973.

Sobre el análisis de políticas públicas pueden verse M.BELTRán, •El policy analysis como instrumento de valoración de la acción pública-, Revista de Estudios Politicos n⿳0 56, 1987, y J.SUBIRaTs, Análisis de políticas públicas y eficacia de la Administración, Instituto Nacional de Administración Pública, Madrid 1989. También de SuBıRATS, -La $\Lambda$ dministración pública como problema. El análisis de políticas públicas como propuesta., en el excelente monográfico sobre $\cdot$ Políticas públicas y organización administrativa. de la revista Documentación Administrativa, $\mathrm{n}^{2}$ 224-225, oct.1990-marzo 1991. Pueden consultarse con provecho el libro de I.MfNY y J.C.ThOENIG, Las politicas públicas, Ariel, Barcelona 1992, y la muy completa $2^{2}$ ed. del de W.N. Dunn, Public Policy Analysis. An Introduction, Prentice-Hall, Englewood Cliffs 1994. No debe olvidarse un clásico de la Ciencia Política: el libro de Ch.E.LindBlom, El proceso de elaboración de políticas públicas, Ministerio para las Administraciones Públicas, Madrid 1991.

Para el análisis de políticas en España véase J.SuBIRATS, Un problema de estilo. La formación de políticas puiblicas en España, Centro de Estudios Cons- 
titucionales, Madrid 1992; también M.Beltrín, La productividad de la Administración española: un análisis comparativo, Instituto de Estudios de Prospectiva, Madrid 1991, que incluye referencias al problema de la calidad de los servicios; tienen interés los casos estudiados por X.BALlarT, ¿Cómo evaluar programas y servicios públicos? Aproximación sistemática y estudios de caso, Ministerio para las Administraciones Públicas, Madrid 1992, así como los reco- gidos en el $n^{\circ}$ 224-225 de Documentación Administrativa antes mencionado, y en el $n^{\circ} 3$ de la revista Gestión y Análisis de Políticas Públicas, que contiene asimismo alguna referencia a la evaluación de la calidad. Puede también consultarse el libro de J.BAREa y A.Gómez CiRIA, El problema de la eficiencia del seclor público en España. Especial consideración de la sanidad, Instituto de Estudios Económicos, Madrid 1994. 